\title{
Vacant Properties and Violence in Neighborhoods
}

\author{
Charles C. Branas, ${ }^{1}$ David Rubin, ${ }^{2}$ and Wensheng Guo ${ }^{1}$ \\ ${ }^{1}$ Department of Biostatistics and Epidemiology, University of Pennsylvania, Philadelphia, PA, USA \\ ${ }^{2}$ Division of General Pediatrics, Children's Hospital of Philadelphia, Philadelphia, PA, USA
}

Correspondence should be addressed to Charles C. Branas, cbranas@upenn.edu

Received 24 August 2012; Accepted 10 September 2012

Academic Editors: R. E. Fullilove, C. Rissel, and M. H. Stigler

Copyright ( 92012 Charles C. Branas et al. This is an open access article distributed under the Creative Commons Attribution License, which permits unrestricted use, distribution, and reproduction in any medium, provided the original work is properly cited.

\begin{abstract}
Objectives. Violence remains a significant public health issue in the United States. To determine if urban vacant properties were associated with an increased risk of assaultive violence and if this association was modified by important neighborhood institutions (e.g., schools, parks/playgrounds, police stations, and alcohol outlets). Methods. Longitudinal ecologic study of all 1816 block groups in Philadelphia. Aggravated assault and vacant property data were compiled yearly from 2002 to 2006 and linked to block groups. A mixed effects negative binomial regression model examined the association of vacant properties and assaults between and within block groups. Results. Among all block groups, 84\% experienced at least one vacant property, 89\% at least one aggravated assault, and $64 \%$ at least one gun assault. Between block groups, the risk of aggravated assault increased $18 \%$ for every category shift of vacant properties (IRR 1.18, 95\% CI: 1.12, 1.25, P<0.001). Parks/playgrounds and alcohol outlets potentially modified the association between vacant properties and aggravated assaults but only at low levels of vacancy. Conclusions. Increasing levels of vacancy were associated with increased risk of assaultive violence in urban block groups.
\end{abstract}

\section{Introduction}

Despite declining rates since the 1990s [1], violence remains a significant public health issue in the United States. As evidence of this, many major cities, such as Philadelphia, have seen consistently increasing rates of aggravated assault despite national trends to the contrary [2]. Leadership continue to seek evidence-based violence reduction strategies that can be readily implemented and that resonate with community members.

Various factors that may influence violence have been well researched [3-10], in particular behavioral risk factors. While some of these factors have been tied to intervention strategies, the relationship of physical structures to rates of violence has been less well proven as a potential modifiable target for intervention. Indeed neighborhood physical disorder remains a consistent concern for community leaders and residents $[11,12]$ and may be associated with aggravated assault [13].

Vacant properties have been alluded to as key, highly modifiable, and easily palpable signs of physical disorder that may also be specifically related to the commission of aggravated assault [14]. Vacant lots and buildings potentially offer refuge to criminal and other illegal activity and very visibly symbolize that a neighborhood has deteriorated, that no one is in control, and that violent or criminal behavior is welcome to proceed with little if any supervision [15]. This Broken Windows theory [16] has led to initiatives that have sought to reduce violence by restoring deteriorating neighborhoods and sealing or removing vacant buildings $[17,18]$.

The study of violence and associated behavioral and environmental risk factors has a long history and is certainly multidisciplinary. Empirical evidence, however, has been sparse and limited in its ability to strongly connect vacant properties and aggravated assault. Prior studies have been either cross-sectional, have been limited in studying causality, or have bundled vacant properties into other indices of physical disorder without specifically studying it as an independent factor $[14,19-22]$. In order to better quantify the relationship between vacant properties and aggravated assault, we obtained multi-year small-area data in a major USA city under the hypotheses that the locations of vacant properties and aggravated assaults 
would be strongly associated and that changes in vacant properties within neighborhoods over time would impact the risk of assault. We also hypothesized that the relationship between vacant properties and aggravated assault might be modified by other neighborhood institutions, such as schools, parks/playgrounds, police stations, and alcohol outlets, which have been noted in prior studies to influence the likelihood of violence or criminal activity [23-26].

\section{Methods}

Longitudinal data on aggravated assault and vacant properties within neighborhood units of Pennsylvania's Philadelphia County (synonymous with the city of Philadelphia) were obtained between 2002-2006. This time period was chosen based on the availability of vacant property data within the city. The Cartographic Modeling Laboratory [27] at the University of Pennsylvania provided the data used in the analysis. The Institutional Review Board at the University of Pennsylvania approved the study.

Philadelphia County was chosen as the site for the study in part because of its violence rates that exceed national rates [2, 28-30]. The unit of analysis was the Census block group. Block groups are smaller geographic units than Census tracts [31] and can be considered geographic markers of neighborhood subunits or "pockets". Although geographically larger than blocks, block groups may still afford greater precision in studying spatial relationships than larger Census tracts [22]. The average land area of a block group in Philadelphia is 0.07 square miles. The study sample consisted of all 1816 block groups in Philadelphia County. The completeness of data allowed us to include all block groups, thereby reducing the likelihood of selection bias, improving the power of the study by increased sample size, and increasing the potential generalizability of the study.

2.1. Primary Independent Variable: Vacant Properties. The USA Postal Service was the source of data on vacant properties. Vacant properties included residential and commercial properties, as well as vacant lots and parcels of land. Any property which was uninhabited or at which mail service was not collected for a period of 90 days was classified as vacant by the Postal Service in its records [32]. The USA Postal Service provides locations of vacant properties to the Cartographic Modeling Laboratory (CML) on at least an annual basis, and the CML then uses geographic information systems technology to geocode these data. Vacant property data were calculated yearly from 2002-2006.

2.2. Dependent Variables: Aggravated Assaults, Gun Assaults, Nongun Assaults. Aggravated assaults between 2002-2006, provided by the Philadelphia Police Department to the CML, were defined as "an unlawful attack by one person upon another for the purpose of inflicting severe or aggravated bodily injury." [33] The primary outcome was the number of total aggravated assaults geocoded within block groups. Given the predominance of firearms as the method of nonfatal and fatal injuries [34], subanalyses of gun assaults and nongun assaults were also performed.
2.3. Other Independent Variables. We considered many demographic and socioeconomic characteristics of block groups that could potentially act as confounders to the association between vacant properties and aggravated assault based on previous violence and crime studies. The variables considered were geographic size (land area) [22], population (total population and population density) [14, 22, 35-37], age (median age) $[14,38,39]$, gender (male to female ratio) $[37,38,40]$, race (number of white residents, number of black residents) $[30,36,41,42]$, ethnicity (number of Hispanic residents) [36, 38], racial segregation (diversity index) [14, 43], economic disadvantage (median household income, poverty level, and unemployment) [39, 42, 44], education (high school diploma rate and bachelor degree rate) [45], family structure (single-parent households) [14, $39,42]$, residential tenure (number of owner versus renteroccupied properties) $[9,20,42]$, and land use (number of residential versus commercial properties) $[36,44,46]$. The variables were compiled using 2004 U.S. Census Bureau estimates, the midpoint of the study period. These variables were encoded as time invariant over the study period.

In order to determine the independent variables that would be included in the regression model, four steps were performed. First, significance testing $(P<0.10)$ of each independent variable with aggravated assault was performed. Second, Spearman correlation coefficients between the independent variables were calculated to test for collinearity (defined as $\rho>0.70$ ). Third, variance inflation factor analysis was performed to test for collinearity (defined as VIF > 10) [47]. Finally, theoretical justification based on evidence from previous studies and our judgment was also used to determine the variables included in the final model. If two variables were collinear, only one variable was selected for the final regression model based on its statistical association with aggravated assault and theoretical plausibility of acting as a confounder. Land area and male to female ratio had $P$ values greater than $0.10(P=0.778$ and $P=0.938$, resp.). Male to female ratio was maintained in the multivariable model given gender differences in violence rates [30]. The following variables were collinear: (1) the number of white residents and black residents, (2) the number of Hispanic residents and the diversity index, and (3) poverty level and median household income $(\rho>0.70)$. We selected black residents, Hispanic residents, and median household income for the multivariable model given their use in previous studies. Using this method of independent variable selection, we decided upon 11 block group-level variables for analysis: (1) year, (2) population, (3) median age, (4) male to female sex ratio, (5) number of black residents, (6) number of Hispanic residents, (7) median household income, (8) number of unemployed residents, (9) number of residents with a Bachelor's degree, (10) number of single parent households, and (11) number of residential properties.

2.4. Interaction Effects. In order to address whether the association between vacant properties and aggravated assault was modified by institutional factors, we studied the impact of schools (measured as schools, colleges, universities, and libraries), parks/playgrounds (measured 
as parks, playgrounds, recreation centers, and cemeteries), police/fire stations (measured as police stations, fire stations, hospitals, and health centers), houses of worship, and alcohol outlets. We were interested in exploring whether the presence of schools, parks/playgrounds, and police/fire stations would reduce the risk of aggravated assault, postulating that the presence of these institutions might promote increased surveillance of the areas around the institutions and deter violent incidents due to the increased likelihood of being caught. We hypothesized that alcohol outlets would increase the risk of aggravated assault by having a synergistic effect with vacant properties that would facilitate violent or criminal behavior [48]. Each of the neighborhood institutions was studied as a dichotomous variable (presence or absence of each institution).

2.5. Data Analysis. We initially calculated summary statistics for each variable in the regression model. We examined both the cumulative summary statistics (2002-2006) and the yearly statistics for the dependent and primary independent variables. We further visualized the distribution of the variables by generating histograms, box plots, and stemand-leaf plots of each variable. The assault variables were classified as a count, that is, the number of assaults per block group.

To further describe our data, we examined the spatial distribution of aggravated assault and vacant properties using kernel density estimation. Kernel density estimation offered visual analysis of the spatial patterns of aggravated assaults and vacant properties. It took into account the spatial proximity of observations (i.e., assaults or vacant properties) without the constraint of the geographic boundaries of block groups. The method estimated a probability density function from the number of observations and when mapped depicted the spatial intensity of the observations (those with higher intensity are termed "hot spots" to denote clustering of an observation) [49]. In addition, to describe the unadjusted relationship between vacant properties and aggravated assault, we constructed a scatterplot, in which the average number of aggravated assaults within block groups sharing the same number of vacant properties were plotted across all values of vacant properties observed in the city. Individual points were displayed as circles, in which the area was proportional to the number of block groups contributing data for a specific vacancy value.

Given that the dependent variable of assault was a count variable and right skewed, we specified our multivariable models using negative binomial regression. We conducted a population-averaged analysis using generalized estimating equations (GEEs) to examine longitudinally the association of vacant properties and aggravated assault, incorporating time as a fixed effect [50]. We decided upon this method because the data were a panel of subjects (i.e., block groups) for which we had repeated measures of events (i.e., assaults and vacant properties) over a five-year period. The final regression model included the aforementioned 10 independent variables and time expressed as a categorical year variable. Other model specifications were a negative binomial family structure, an unstructured correlation which imposed no preconceived notions about the correlations of the assaults within block groups over time [51], and a robust command which produced valid standard errors even if the specified correlation structure was not correct [50].

Given the skewness of the primary independent variable of vacant properties, we first categorized it according to pentile cutpoints. We examined the estimates of the coefficients by including it as a nominal variable and discovered a linear trend in the coefficients. We therefore included the categorized variable as an ordinal covariate in the final analysis. A mean ordinal variable was created which represented the mean of the ordinal vacant property variable of a block group over the five-year study period. Each block group therefore had five values of the ordinal vacant property variable for each year of the study and one value of the mean ordinal vacant property variable. The ordinal vacant property variable allowed us to measure the within block group effect of changes in vacancy, as the value of this variable could change year to year within a block group. However, the mean ordinal variable allowed between block group comparisons because it represented the average vacancy category for an individual block group over the study period, thereby removing the potential within block group changes. Both the ordinal vacant property variable and the mean ordinal variable were included in the regression model. Finally, after model specification, potential effect modifiers (i.e., schools, parks/playgrounds, houses of worship, police/fire stations, and alcohol outlets within block groups) were tested sequentially in individual models to determine their relationship to the association between vacant properties and aggravated assault.

\section{Results}

The study sample consisted of all 1816 block groups in Philadelphia County. The demographic and socioeconomic characteristics of the block groups are depicted in Table 1. During the five-year study period, the majority of block groups in Philadelphia County had aggravated assaults and vacant properties; $89 \%$ of the block groups experienced one or more aggravated assaults, with a median of 4 . Gun assaults, although lower in frequency than nongun assaults, still occurred in the majority of block groups; $64 \%$ of block groups experienced one or more gun assaults, with a median of 1 . Vacant properties were also widely present; $84 \%$ of the block groups had one or more vacant properties, with a median of 6 .

Examining the unadjusted relationship between vacant properties and aggravated assault revealed a significant overlap of higher aggravated assault rates in block groups with higher levels of vacant properties. Comparing the kernel density maps of vacant properties, total aggravated assaults, and gun assaults provided a spatial visualization of the distribution of vacant properties and aggravated assaults, with the darker color intensity signifying a higher density of vacant properties or assaults (Figure 1). Furthermore, there was a near linear correlation between vacant properties and aggravated assaults in unadjusted analysis $(P<0.001$, Figure 2$)$. 
TABLE 1: Summary statistics and years of data pertaining to the 1816 blockgroups in Philadelphia County.

\begin{tabular}{lcr}
\hline & Mean (SD) & Median (IQR 25\%, 75\%) \\
\hline All assaults (2002-2006) & $5.28(4.97)$ & $4[2,7]$ \\
Gun assaults (2002-2006) & $1.77(2.25)$ & $1[0,3]$ \\
Nongun assaults (2002-2006) & $3.51(3.50)$ & $3[1,5]$ \\
No. of vacant properties (2002-2006) & $12.53(16.67)$ & $6[1,18]$ \\
Total population (2004) & $792.45(507.09)$ & $711.5[455.5,1003.5]$ \\
Median age (2004) & $34.85(8.35)$ & $35[30.6,38.85]$ \\
Male : female ratio (2004) & $0.89(0.52)$ & $0.9[0.8,0.9]$ \\
No. of black residents (2004) & $353.22(353.42)$ & $248[55.5,575.5]$ \\
No. of Hispanic residents (2004) & $69.18(136.70)$ & $20[7,62]$ \\
Median household income (2004) & $35297(20046)$ & $33213[22281,44645]$ \\
No. of unemployed (2004) & $42.18(40.65)$ & $31[13,61]$ \\
No. of with bachelor's degree (2004) & $78.88(105.31)$ & $43.84[14.80,100.84]$ \\
No. of single parent households (2004) & $90.94(60.56)$ & $83[46,125]$ \\
No. of residential properties (2004) & $253.40(158.70)$ & $238[143,340]$ \\
\hline
\end{tabular}

${ }^{*}$ SD: standard deviation; IQR: interquartile range.

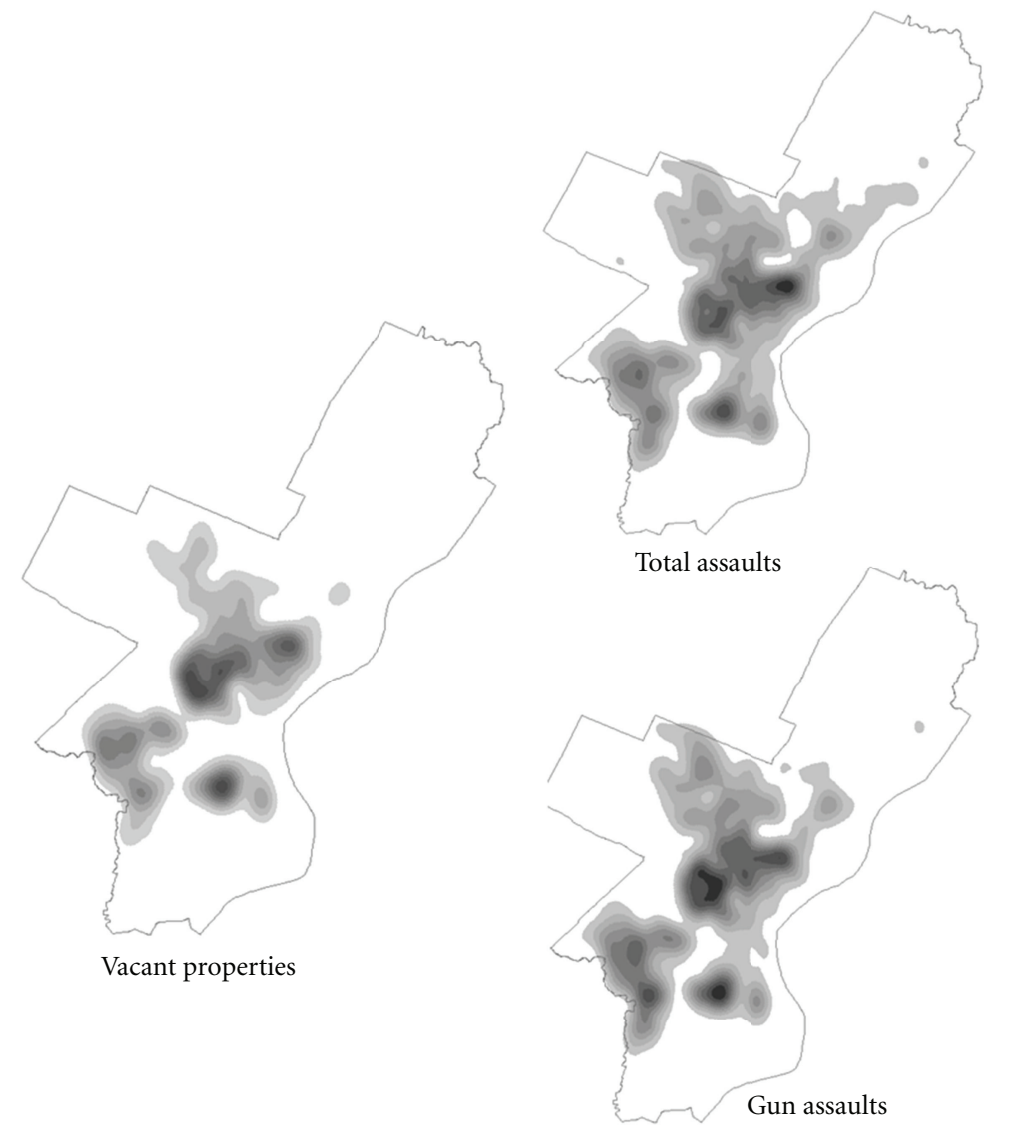

FIGURE 1: Kernel density maps of vacant properties and aggravated assaults.

After adjusting for the demographic and socioeconomic covariates, vacant properties remained associated with the risk of aggravated assault (Table 2). Moreover, although many of the covariates had a statistically significant association, vacant properties had the strongest association, both in effect size and $P$ value. There was also a doseresponse relationship between vacant properties and the expected number of assaults (Figure 3). Although there was an association between vacant properties and the risk of aggravated assault between block groups over time, there 
TABLE 2: Multivariable analyses of the relationships between vacant properties and assaults in Philadelphia County from $2002-2006$.

\begin{tabular}{|c|c|c|c|}
\hline & All assaults & Gun assaults & Nongun assaults \\
\hline \multirow{2}{*}{ Vacant properties } & $0.1678^{\S}$ & $0.2055^{\S}$ & $0.1359^{\S}$ \\
\hline & {$[0.1135,0.2222]$} & {$[0.1297,0.2813]$} & {$[0.0787,0.1931]$} \\
\hline \multirow{2}{*}{ Total population } & $0.0004^{\S}$ & $0.0001^{\S}$ & $0.0005139^{\S}$ \\
\hline & {$[0.0002,0.0006]$} & {$[-0.0001,0.0002]$} & {$[0.0003,0.0007]$} \\
\hline \multirow{2}{*}{ Median age } & $-0.0080^{\dagger}$ & -0.0075 & $-0.0077^{\dagger}$ \\
\hline & {$[-0.0151,-0.0008]$} & {$[-0.0159,0.0010]$} & {$[-0.0143,-0.0010]$} \\
\hline \multirow{2}{*}{ Male: female ratio } & $0.1162^{\ddagger}$ & 0.0046 & $0.1573^{\S}$ \\
\hline & {$[0.0337,0.1988]$} & {$[-0.0362,0.0455]$} & {$[0.0688,0.2457]$} \\
\hline \multirow{2}{*}{ No. of black residents } & 0.0001 & $0.0004^{\S}$ & 0.0000204 \\
\hline & {$[-8.63 e-06,0.0003]$} & {$[0.0002,0.0005]$} & {$[-0.0002,0.0002]$} \\
\hline \multirow{2}{*}{ No. of Hispanic residents } & $0.0005^{\S}$ & $0.0005^{\S}$ & $0.0005^{\S}$ \\
\hline & {$[0.0003,0.0007]$} & {$[0.0003,0.0008]$} & {$[0.0003,0.0007]$} \\
\hline \multirow{2}{*}{ Median household income } & $-9.17 e-06^{\S}$ & $-0.0000103^{\S}$ & $-9.02 e-06^{\S}$ \\
\hline & {$[-0.00014,-4.36 e-06]$} & {$[-0.000153,-5.36 e-06]$} & {$[-0.00014,-4.07 e-06]$} \\
\hline \multirow{2}{*}{ No. of unemployed } & $0.0010^{\dagger}$ & $0.0009^{\dagger}$ & $0.0011^{\dagger}$ \\
\hline & {$[0.0001,0.0019]$} & {$[0.0000415,0.0017]$} & {$[0.0001,0.0022]$} \\
\hline \multirow{2}{*}{ No. of with bachelors degree } & $-0.0010^{\ddagger}$ & -0.0006 & $-0.0011^{\ddagger}$ \\
\hline & {$[-0.0016,-0.0004]$} & {$[-0.0011,0.0000327]$} & {$[-0.0018,-0.0004]$} \\
\hline \multirow{2}{*}{ No. of single-parent households } & $0.0027^{\S}$ & $0.0048^{\S}$ & $0.0017^{\dagger}$ \\
\hline & {$[0.0014,0.0040]$} & {$[0.0037,0.0059]$} & {$[0.0001,0.0034]$} \\
\hline \multirow{2}{*}{ No. of residential properties } & $-0.0008^{\S}$ & $-0.0008^{\S}$ & $-0.0007^{\S}$ \\
\hline & {$[-0.0012,-0.0004]$} & {$[-0.0012,-0.0004]$} & {$[-0.0011,-0.0003]$} \\
\hline
\end{tabular}

${ }^{*}$ Shown in brackets are $95 \%$ confidence intervals; ${ }^{\dagger} P<0.05 ;{ }^{\ddagger} P<0.01 ;{ }^{\S} P<0.001$.

was no statistically significant association between changes in vacant properties within block groups and the risk of assault within those block groups over time. However, less than 5\% of block groups actually changed from one category of vacant properties to another during the five-year period.

In tests for interactions, alcohol outlets and parks/playgrounds within block groups appeared to modify the relationship between vacant properties and aggravated assault, while schools, houses of worship, and police/fire stations did not $(P<0.001$, Figure 4$)$. For alcohol outlets and parks/playgrounds, the interaction effects were similar: block groups with these attributes had higher rates of aggravated assaults than block groups without these attributes, but only at lower levels of vacant properties. At higher levels of vacant properties, aggravated assaults were both higher and indistinguishable between the two groups. With a higher baseline of assaults in block groups with these attributes, the rate of increase in aggravated assault as one moved between each category of vacant properties was therefore less steep.

\section{Discussion}

In this analysis of violence in neighborhoods, we found a significant association between vacant properties and the risk of aggravated assault-and particularly gun assaultseven after controlling for important demographic and socioeconomic characteristics of the neighborhoods. Vacant properties also had the strongest effect size, prevailing over almost a dozen well-known indicators of disadvantage. Furthermore, there was evidence of a dose-response relationship, in that the risk of aggravated assault in block groups with higher levels of vacant properties was greater than in block groups with lower levels of vacant properties. Finally, we noted that in block groups with parks/playgrounds or alcohol outlets there were higher adjusted rates of aggravated assault comparatively at lower levels of vacancy that was washed out in block groups with higher levels of vacancy, for which assault rates were universally high.

These data potentially identify vacant properties as a modifiable target for intervention to reduce assaults in disadvantaged neighborhoods. However, we would urge caution in interpreting the data given the need to demonstrate generalizability of the findings to other cities and regions of the USA and the limited ability from our observational design to infer causality. For example, the possibility of unmeasured confounders that could explain the association between vacant properties and aggravated assault remains plausible, particularly without within-block group changes to strengthen causal inference. However, the proportion of the model variance explained by vacant properties far outweighed the contribution of all other factors in the model, and upon more detailed analysis, our study period was not 
of sufficient length to study the within-block group effect. In fact, less than $5 \%$ of block groups experienced a change in the category of vacant properties during the study period. A longer study period in which more change in the number of vacant properties within block groups may have occurred could potentially improve the likelihood of observing an association and would be an important area for future research. Aside from concerns of unobserved confounding, spillover effects of vacant properties and aggravated assault that may have occurred between block groups might also have biased our results and were unmeasured in this analysis. While spillover was certainly possible, we believe it less likely that it would have erased the strong association found between vacant properties and aggravated assault. Finally, we recognize that there is heterogeneity in the types of vacant properties which this study did not examine (e.g., sealed versus open properties, buildings versus lots/parcels of land, properties littered with trash and graffiti versus properties with clean surrounding areas, commercial building, or brownfield versus residential building). Further study can be performed to determine whether the different types of vacant properties have the same relationship to aggravated assault.

Despite these limitations, our findings add to the quality of evidence on the relationship between vacant properties and aggravated assault. Previous studies have supported the association between neighborhood physical disorder and violence [19, 20, 52-57]. Skogan found an association between disorder and crime; however, much of the analyses were correlational and cross-sectional [19]. Taylor's work on Baltimore neighborhoods challenged that it was neighborhood disadvantage rather than an index of physical incivilities which included vacant properties that predicted later crime [21]. While his work was important because of its longitudinal design, vacant properties were not studied as an independent variable. Spelman examined vacant properties independently and found that blocks with abandoned buildings had twice the drug and property crime rates than blocks without abandoned buildings [20]. However, his design may have been prone to overmatching and was of limited generalizability since he only studied one, low-income neighborhood in Austin, TX, USA. Accordino's work documented the problem posed by vacant and abandoned properties; however, it was a survey of local officials to the economic and social revitalization of central cities [17]. Finally, Fullilove's ethnographic study was designed specifically to examine the social impact on residents who moved from neighborhoods deteriorated by the loss of housing and abandonment to redeveloped communities [18].

An added strength of our study was that beyond the association we observed, we also began to consider the influence of other institutional factors within neighborhoods that may influence the relationship between vacant properties in aggravated assault. In so doing, we found an interaction among block groups that had open spaces (parks/playgrounds) and among those with alcohol outlets. Compared to block groups without these factors, there was a greater risk of aggravated assault, but only when levels of vacancy were low. Their relationship to aggravated assault was attenuated at higher levels of vacancy.

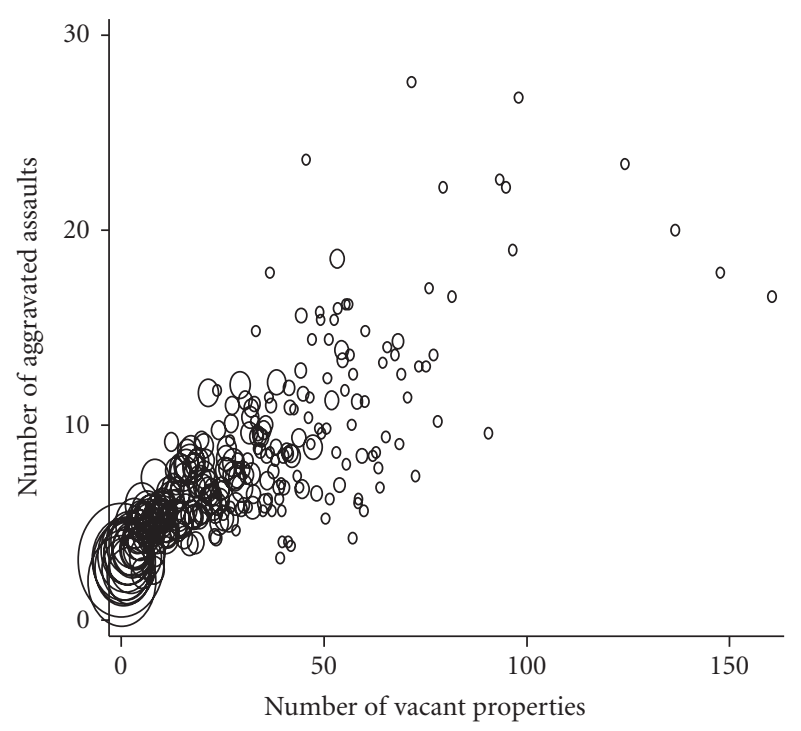

FIGURE 2: Unadjusted association between vacant properties and aggravated assaults across 1816 block groups in Philadelphia County between $2002-2006^{*}$. *Area of circles proportional to the number of block groups with level of vacant properties.

One potential explanation for the higher rates of assaults in block groups with parks/playgrounds might be the potential for criminal or violent activity in unsupervised open space, and alcohol outlets have been studied as facilitating violent behavior $[14,48,58]$. Yet, our results would suggest that the presence of police stations alone in block groups with these attributes is unlikely to mitigate the intensity of aggravated assault in our most disadvantaged neighborhoods, without a concurrent strategy to reduce the physical disorder that may be a source for increased violence. The lack of significant findings with other neighborhood institutions (i.e., schools, houses of worship, and police/fire stations) may be that the frequency of assaults is related not only to these physical structures within the block groups but also the surveillance strategies around these particular institutions. For example, the policing strategies of the block groups were not examined in this study (e.g., street cameras, park, and walk patrol strategies). An additional limitation of these interaction findings is that time of day was not accounted for and may influence the role of these other neighborhood institutions. Further study would be warranted to understand these potential relationships.

This growing body of evidence on physical disorder in neighborhoods may justify the support of interventions to address this type of disorder, such as the abatement of vacant properties. While enhancing the cohesion among residents in neighborhoods [9] is an important effort, it is challenging, especially in areas with high levels of residential transiency. Initiatives to reduce the physical disorder of neighborhoods may complement these efforts as a holistic approach to reducing violence in neighborhoods. Vacant properties are often permanent structures of the built environment that if addressed may impact the vitality of neighborhoods and populations at large. 


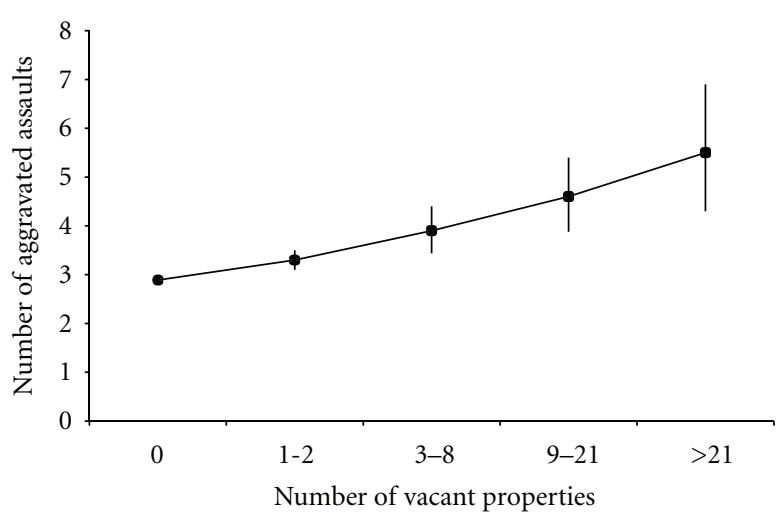

(a) All aggravated assaults

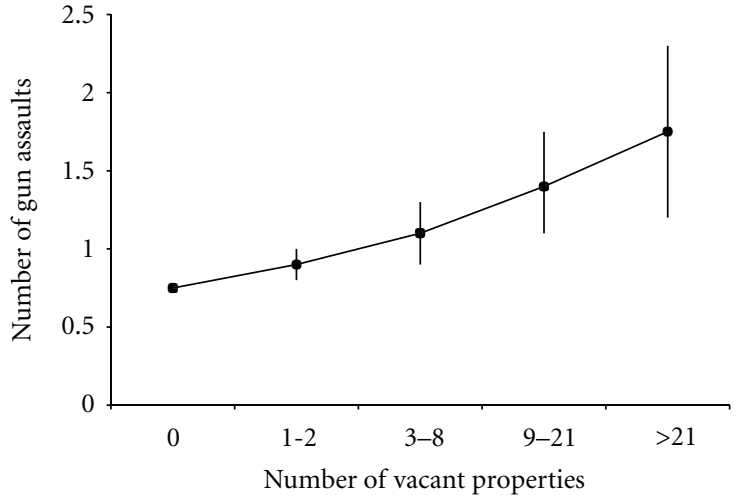

(b) Gun assaults

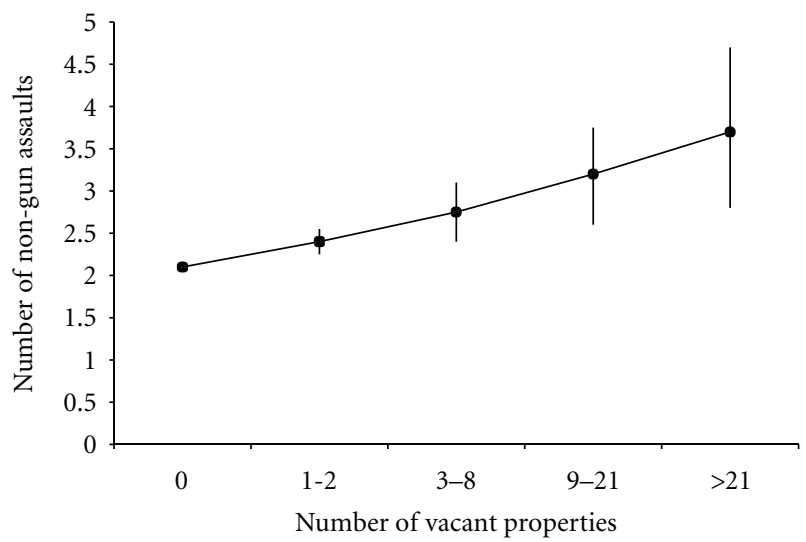

(c) Nongun assaults

FiguRE 3: Adjusted assault rates across categories of vacant properties in Philadelphia County between 2002 and $2006 *$

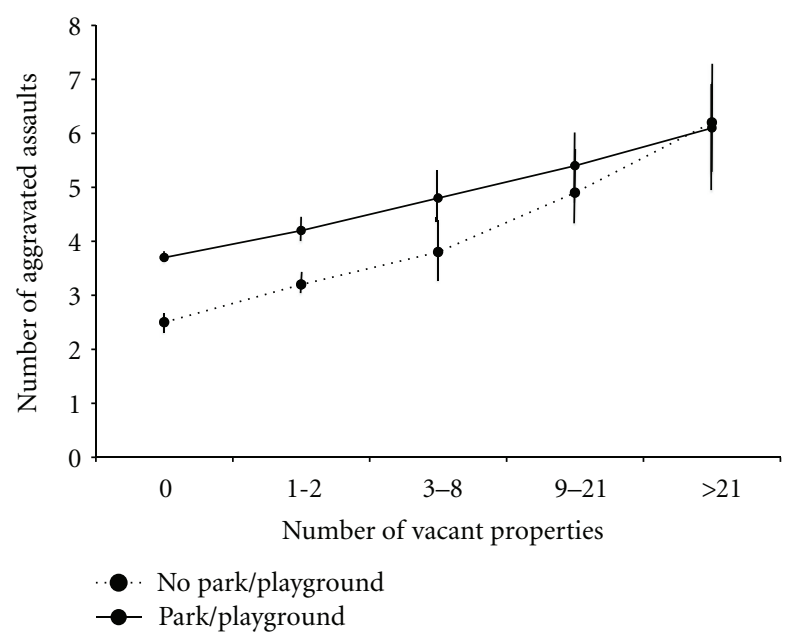

(a) Parks/playgrounds

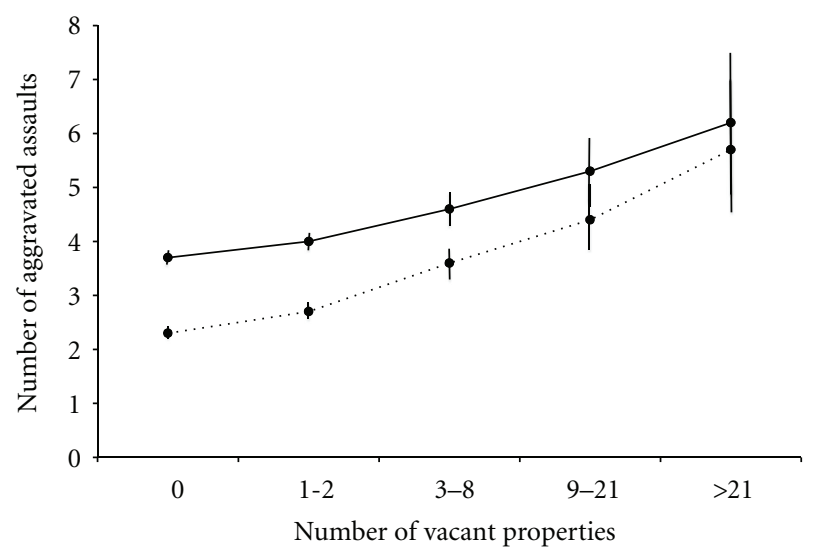

-. No alcohol outlets

- Alcohol outlets

(b) Alcohol outlets

FIGURE 4: Influence of neighborhood institutions on the relationship between vacant properties and assaults in Philadelphia County from 2002-2006*.

\section{Conclusion}

Several vacancy abatement strategies exist, such as demolition, restoration/rehabilitation, property stabilization (i.e., cleaning and sealing vacant properties), and neighborhood beautification (e.g., greening areas around vacant properties) [59-61]. Partnership between city agencies and community members is critical in devising a strategic plan for vacant 
property management and oversight. Furthermore, affected cities need to be prepared to address the cost and time associated with abatement programs, the potential for eminent domain disputes, and the goal of avoiding neighborhood gentrification $[15,17]$. In light of the economic recession, it may be worthwhile to focus discussion on the management of vacant properties as the foreclosure crisis is changing the landscape of not only disadvantaged but also previously stable neighborhoods [62-64]. An evidence-based understanding that urban vacant properties and neighborhood violence are fundamentally associated is an important first step before any of such management strategies can be reasonably supported on a large scale by policymakers.

\section{Authors' Contribution}

Dr. C. C. Branas contributed to the design, analysis, drafting, and review of the paper. Drs. D. Rubin and W. Guo contributed to the analysis and review of the paper.

\section{Acknowledgments}

The authors gratefully acknowledge the key contributions and work of Dr. Nadine Gracia and the Cartographic Modeling Laboratory at the University of Pennsylvania. The authors have no conflict of interests or financial disclosures associated with this paper. There are no disclaimers to report. This work was completed in part with funding from the Centers for Disease Control and Prevention (Grant U49CE001093) and the National Institutes of Health (Grants R01AA016187 and R01AA020331).

\section{References}

[1] Federal Bureau of Investigations Uniform Crime Reports, Crime in the United States 2007, http://www2.fbi.gov/ucr/ cius2007/data/table_01.html.

[2] C. C. Branas, T. S. Richmond, D. P. Culhane, T. R. TenHave, and D. J. Wiebe, "Investigating the link between gun possession and gun assault," American Journal of Public Health, vol. 99, no. 11, pp. 2034-2040, 2009.

[3] Youth Violence: A Report of the Surgeon General, U.S. Department of Health and Human Services, Centers for Disease Control and Prevention, National Center for Injury Prevention and Control, Substance Abuse and Mental Health Services Administration, Center for Mental Health Services, and National Institutes of Health, National Institute of Mental Health, Rockville, Md, USA, 2001.

[4] M. D. Resnick, M. Ireland, and I. Borowsky, "Youth violence perpetration: what protects? What predicts? Findings from the National Longitudinal Study of Adolescent Health," Journal of Adolescent Health, vol. 35, no. 5, pp. 424.e1-424.e10, 2004.

[5] P. L. Ellickson and K. A. McGuigan, "Early predictors of adolescent violence," American Journal of Public Health, vol. 90, no. 4, pp. 566-572, 2000.

[6] R. E. Tremblay, D. S. Nagin, J. R. Séguin et al., "Physical aggression during early childhood: trajectories and predictors," Pediatrics, vol. 114, no. 1, pp. e43-e50, 2004.

[7] R. J. Sampson, "The neighborhood context of well-being," Perspectives in Biology and Medicine, vol. 46, no. 3, supplement, pp. S53-S64, 2003.
[8] R. B. Taylor, Crime, Grime, Fear, and Decline: A Longitudinal Look, National Institute of Justice, Research in Brief Vol. 1-12, 1999.

[9] R. J. Sampson, S. W. Raudenbush, and F. Earls, "Neighborhoods and violent crime: a multilevel study of collective efficacy," Science, vol. 277, no. 5328, pp. 918-924, 1997.

[10] B. E. Molnar, M. J. Miller, D. Azrael, and S. L. Buka, "Neighborhood predictors of concealed firearm carrying among children and adolescents: results from the Project on Human Development in Chicago Neighborhoods," Archives of Pediatrics and Adolescent Medicine, vol. 158, no. 7, pp. 657664, 2004.

[11] P. Hermann, Golden memory is supplanted by blood and fear, in The Baltimore Sun, Baltimore, Md, 2008, http://www .baltimoresun.com/news/local/bal-te.md.hermann17dec17, 0, 699173.story.

[12] A. Worden, "Fighting blight a building at a time, in Philadelphia Inquirer, Philadelphia, Pa, USA, 2008," http://fixitphilly .org/fighting-blight-a-building-at-a-time/.

[13] C. C. Branas, D. J. Wiebe, T. S. Richmond, and D. P. Culhane, "Neighborhood disorder and the risk of firearm injury," in American Public Health Association 133rd Annual Meeting and Exposition, Philadelphia, Pa, USA, 2005.

[14] D. W. Roncek and P. A. Maier, "Bars, blocks, and crimes revisited: linking the theory of routine activities to the empiricism of, 'Hot spots', Criminology, vol. 29, no. 4, pp. 725-753, 1991.

[15] D. T. Kraut, "Hanging out the no vacancy sign: eliminating the blight of vacant buildings from urban areas," New York University Law Review, vol. 74, no. 4, p. 1139, 1999.

[16] J. Q. Wilson and G. L. Kelling, "The police and neighborhood safety: broken windows," The Atlantic Monthly, vol. 127, pp. 29-38, 1982.

[17] J. Accordino and G. T. Johnson, "Addressing the vacant and abandoned property problem," Journal of Urban Affairs, vol. 22, no. 3, pp. 301-315, 2000.

[18] M. T. Fullilove, L. Green, and R. E. Fullilove, "Building momentum: an ethnographic study of inner-city redevelopment," American Journal of Public Health, vol. 89, no. 6, pp. 840-844, 1999.

[19] W. G. Skogan, Disorder and Decline: Crime and The Spiral of Decay in American Neighborhoods, Free Press, New York, NY, USA, 1990.

[20] W. Spelman, "Abandoned buildings: magnets for crime?" Journal of Criminal Justice, vol. 21, no. 5, pp. 481-495, 1993.

[21] R. B. Taylor, Breaking Away from Broken Windows: Baltimore Neighborhoods and the Nationwide Fight Against Crime, Grime, Fear, and Decline, Westview Press, Boulder, Colo, USA, 2001.

[22] D. W. Roncek, "Dangerous places: crime and residential environment (Cleveland, San Diego)," Social Forces, vol. 60, no. 1, pp. 74-96, 1981.

[23] P. J. Gruenewald and L. Remer, "Changes in outlet densities affect violence rates," Alcoholism, vol. 30, no. 7, pp. 1184-1193, 2006.

[24] R. Curtis, "The improbable transformation of inner-city neighborhoods: crime, violence, drugs, and youth in the 1990s," Journal of Criminal Law and Criminology, vol. 88, no. 4, p. 1233, 1998.

[25] L. Zhu, D. M. Gorman, and S. Horel, "Alcohol outlet density and violence: a geospatial analysis," Alcohol and Alcoholism, vol. 39, no. 4, pp. 369-375, 2004.

[26] B. A. Lawton, R. B. Taylor, and A. J. Luongo, "Police officers on drug corners in Philadelphia, drug crime, and violent 
crime: intended, diffusion, and displacement impacts," Justice Quarterly, vol. 22, no. 4, pp. 427-451, 2005.

[27] "University of Pennsylvania Cartographic Modeling Laboratory," http://cml.upenn.edu/.

[28] Pennsylvania Department of Health Bureau of Health Statistics and Research, http://www.health.state.pa.us/stats.

[29] Pennsylvania Department of Health, State Health Improvement Plan 2006-2010: Injury and Violence (Chapter 11), http://www.dsf.health.state.pa.us/health/CWP/view.asp?A= $169 \& \mathrm{Q}=243631$.

[30] Centers for Disease Control and Prevention National Center for Injury Prevention and Control, Web-based Injury Statistics Query and Reporting System, http://www.cdc.gov/injury/ wisqars/index.html.

[31] U.S. Census Bureau Cartographic Boundary Files, http://www .census.gov/geo/www/cob/bg_metadata.html\#cbg.

[32] University of Pennsylvania Cartographic Modeling Laboratory NeighborhoodBase, http://cml.upenn.edu/nbase/.

[33] Federal Bureau of Investigations, Uniform Crime Reports Offense Definitions, http://www.fbi.gov/ucr/ucr.htm.

[34] Firearm \& Injury Center at Penn, Firearm Injury in the U.S. Resource Book, http://www.uphs.upenn.edu/ficap/.

[35] R. F. Sing, C. C. Branas, E. J. MacKenzie, and C. W. Schwab, "Geographic variation in serious nonfatal firearm injuries in Pennsylvania," Journal of Trauma, vol. 43, no. 5, pp. 825-830, 1997.

[36] R. J. Sampson and S. W. Raudenbush, "Seeing disorder: neighborhood stigma and the social construction of 'broken windows," Social Psychology Quarterly, vol. 67, no. 4, pp. 319342, 2004.

[37] C. E. Kubrin, "Structural covariates of homicide rates: does type of homicide matter?" Journal of Research in Crime and Delinquency, vol. 40, no. 2, pp. 139-170, 2003.

[38] S. De Coster, K. Heimer, and S. M. Wittrock, "Neighborhood disadvantage, social capital, street context, and youth violence," Sociological Quarterly, vol. 47, no. 4, pp. 723-753, 2006.

[39] C. Cubbin, L. W. Pickle, and L. Fingerhut, "Social context and geographic patterns of homicide among US black and white males," American Journal of Public Health, vol. 90, no. 4, pp. 579-587, 2000.

[40] R. J. Sampson, J. D. Morenoff, and S. Raudenbush, "Social anatomy of racial and ethnic disparities in violence," American Journal of Public Health, vol. 95, no. 2, pp. 224-232, 2005.

[41] E. Wei, A. Hipwell, D. Pardini, J. M. Beyers, and R. Loeber, "Block observations of neighbourhood physical disorder are associated with neighbourhood crime, firearm injuries and deaths, and teen births," Journal of Epidemiology and Community Health, vol. 59, no. 10, pp. 904-908, 2005.

[42] C. Cubbin, F. B. LeClere, and G. S. Smith, "Socioeconomic status and injury mortality: individual and neighbourhood determinants," Journal of Epidemiology and Community Health, vol. 54, no. 7, pp. 517-524, 2000.

[43] ESRI, Methodology Statement: 2010 Diversity Index, http://www.esri.com/library/whitepapers/pdfs/diversity-index -methodology.pdf.

[44] R. J. Sampson and S. W. Raudenbush, "Systematic social observation of public spaces: a new look at disorder in urban neighborhoods," American Journal of Sociology, vol. 105, no. 3, pp. 603-651, 1999.

[45] C. C. Branas, T. S. Richmond, and C. W. Schwab, "Firearm homicide and firearm suicide: opposite but equal," Public Health Reports, vol. 119, no. 2, pp. 114-124, 2004.
[46] R. B. Taylor, B. A. Koons, E. M. Kurtz, J. R. Greene, and D. D. Perkins, "Street blocks with more nonresidential land use have more physical deterioration: evidence from Baltimore and Philadelphia," Urban Affairs Review, vol. 31, no. 1, pp. 120-136, 1995.

[47] L. C. Hamilton, Statistics with STATA: Updated for Version 9, Thomson Brooks/Cole, 2006.

[48] C. C. Branas, M. R. Elliott, T. S. Richmond, D. P. Culhane, and D. J. Wiebe, "Alcohol consumption, alcohol outlets, and the risk of being assaulted with a gun," Alcoholism, vol. 33, no. 5, pp. 906-915, 2009.

[49] Geospatial Analysis - a comprehensive guide, Point density, http://www.spatialanalysisonline.com/output/.

[50] STATA Cross-Sectional Time-Series Reference Manual Release 8., College Station, Tex, USA, Stata Corporation, 2003.

[51] UCLA, Academic Technology Services Statistical Consulting Group, Panel Data Analysis using GEE, http://www.ats.ucla .edu/stat/stata/library/gee.htm.

[52] M. A. Yonas, P. O'Campo, J. G. Burke, and A. C. Gielen, "Neighborhood-level factors and youth violence: giving voice to the perceptions of prominent neighborhood individuals," Health Education and Behavior, vol. 34, no. 4, pp. 669-685, 2007.

[53] R. B. Taylor, S. D. Gotteredson, and S. Brower, "Block crime and fear: defensible space, local social ties, and territorial functioning," Journal of Research in Crime and Delinquency, vol. 21, no. 4, pp. 303-331, 1984.

[54] D. D. Perkins, A. Wandersman, R. C. Rich, and R. B. Taylor, "The physical environment of street crime: defensible space, territoriality and incivilities," Journal of Environmental Psychology, vol. 13, no. 1, pp. 29-49, 1993.

[55] P. O. H. Wikström and R. Loeber, "Do disadvantaged neighborhoods cause well-adjusted children to become adolescent delinquents? A study of male juvenile serious offending, individual risk and protective factors, and neighborhood context," Criminology, vol. 38, no. 4, pp. 1109-1140, 2000.

[56] R. B. Taylor and J. Covington, "Community structural change and fear of crime," Social Problems, vol. 40, no. 3, pp. 374-395, 1993.

[57] G. Kelling, "Measuring what matters: a new way of thinking about crime and public order," National Institute of Justice and Office of Community Oriented Policing Services Research Report, 1999.

[58] M. Livingston, "A longitudinal analysis of alcohol outlet density and assault," Alcoholism, vol. 32, no. 6, pp. 1074-1079, 2008.

[59] Vacant Land in Philadelphia: A Report on Vacant Land Management and Neighborhood Restructuring Philadelphia City Planning Commission: Philadelphia, Pa, USA, 1995.

[60] J. Schilling and J. Logan, "Greening the rust belt: a green infrastructure model for right sizing America's shrinking cities," Journal of the American Planning Association, vol. 74, no. 4, pp. 451-466, 2008.

[61] The Pennsylvania Horticultural Society Philadelphia Green, Transforming Urban Abandoned Land into Community Assets: Philadelphia Green's Vacant Land Management Project, 2008.

[62] E. Eckholm, Foreclosures Force Suburbs to Fight Blight in The New York Times, New York, NY, USA, 2007.

[63] C. Duhigg, Fannie Mae Lets Renters Stay Despite Foreclosures in The New York Times, New York, NY, USA, 2008.

[64] C. Torres, Market for Mortgages Shrinks, in The Washington Post, Washington, DC, USA, 2008. 


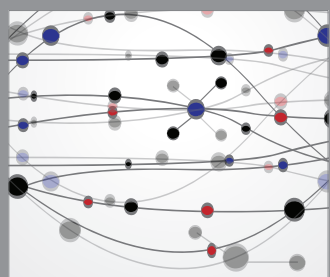

The Scientific World Journal
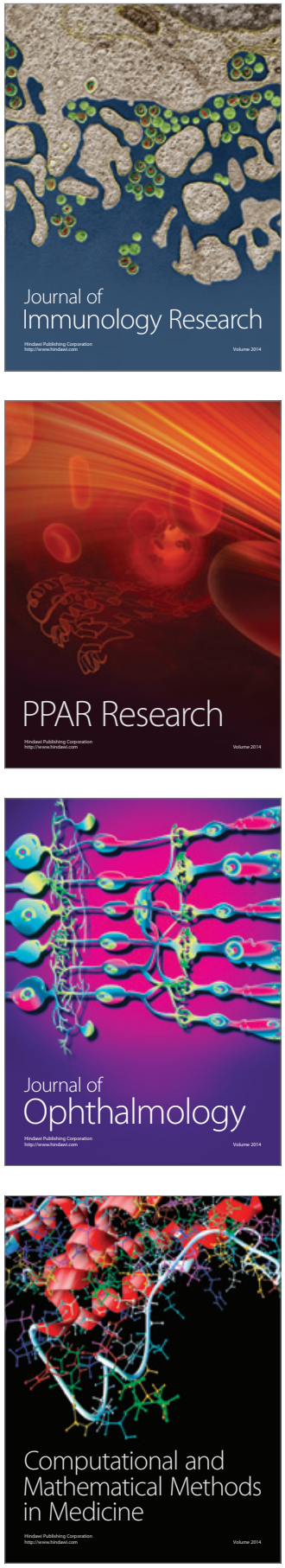

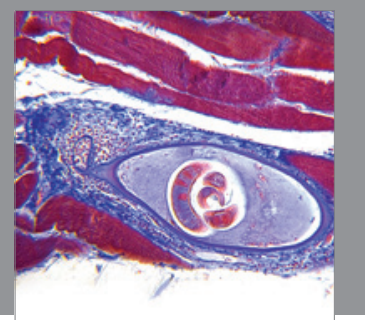

Gastroenterology

Research and Practice
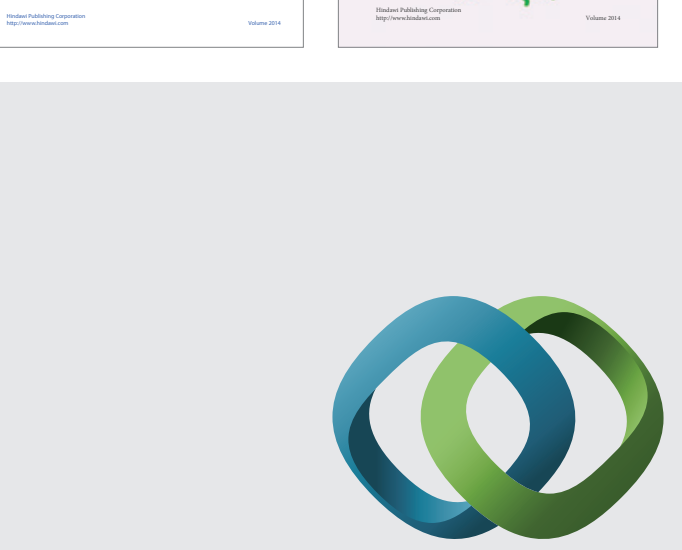

\section{Hindawi}

Submit your manuscripts at

http://www.hindawi.com
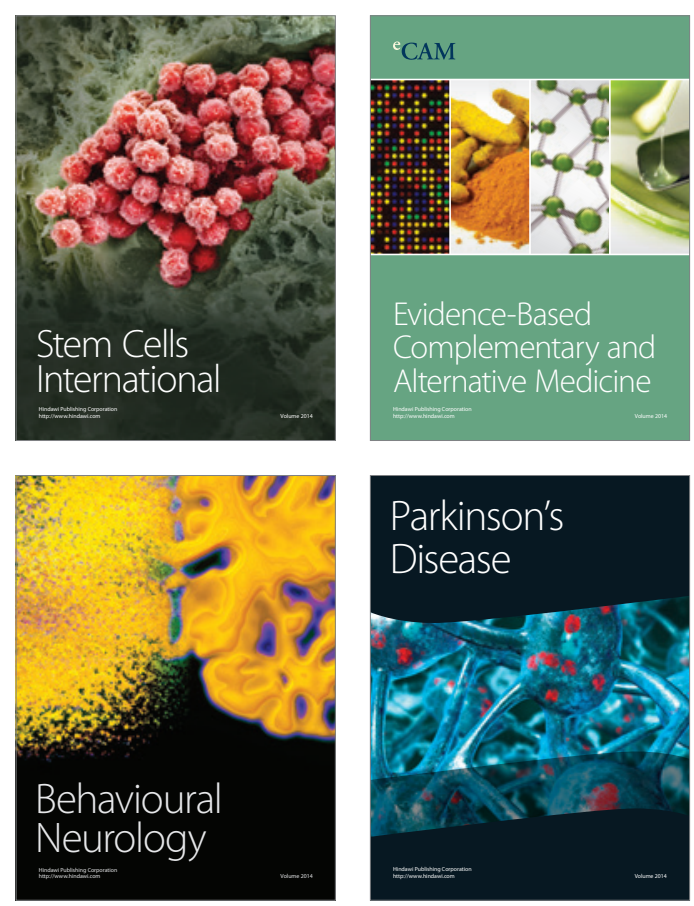

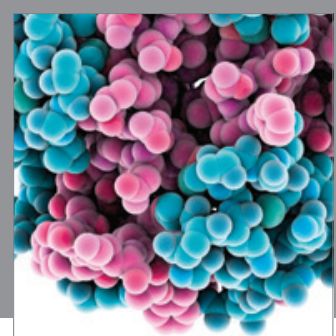

Journal of
Diabetes Research

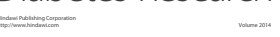

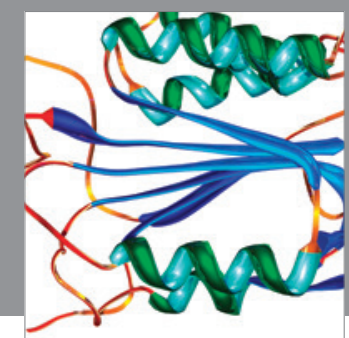

Disease Markers
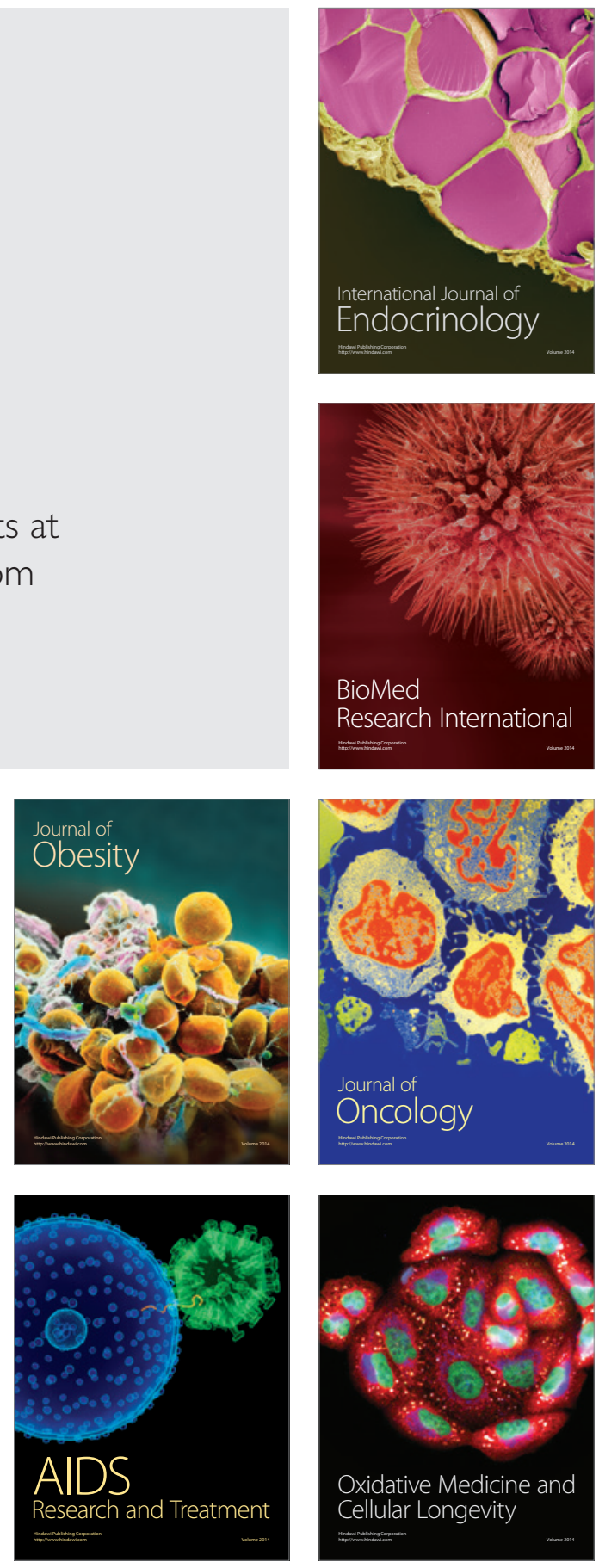